PROCEEDINGS OF THE WORLD CONFERENCE ON OZONE THERAPY IN MEDICINE, DENTISTRY AND VETERINARY. ANCONA (ITALY). SEPTEMBER 22nd - 23rd - 24th, 2017

\title{
Possible errors in pain treatment with ozone [abstract]
}

\section{Stefan Tiron}

Romania

\section{ABSTRACT}

\section{OPEN ACCESS}

\section{Citation}

Tiron S. Possible errors in pain treatment with ozone [abstract]. Proceedings of The World Conference on Ozone Therapy in Medicine, Dentistry and Veterinary. Ancona (Italy). September 22nd - 23rd - 24th , 2017. J Ozone Ther. 2019;3(4):73. doi: 10.7203/jo3t.3.4.2019.15546

Academic Editor Jose Baeza-Noci, School of Medicine, Valencia University, SPAIN

\section{Editor}

World Federation of Ozone Therapy, Bolgna, ITALY

\section{Received} June 17, 2019

\section{Accepted}

December 08, 2019

Published

December 30, 2019

Intellectual Property

Stefan Tiron.

This is an open access article distributed under the terms of the Creative Commons Attribution License (CC BY 4.0), which permits unrestricted use, distribution, and reproduction in any medium, provided the original author and source are credited.

\section{Author Information}

tironstefan@yahoo.com
This presentation is made based on (more than) 3000 patient's experience.

The pain treatment with ozone is an excellent one. So ... why don't we have $100 \%$ results?

\section{1.- WRONG DIAGNOSIS :}

A. Treatment of an irradiate pain like a local one: every pain in

- Upper limb (with no evident cause): must be treated like an irradiate cervical problem, and treated in cervical region.

- Lower limb ( with no evident cause ): must be treated like an irradiate lumbar problem and treated in lumbar region.

B. Traumatical or surgical scars in cervical or abdominal region can explain cervical or lombar pain. The treatment must begin with subcutaneous ozone injections in the pericicatricial region.

C. Pain given by chronic fatigue syndrome

- Treatment in diseases when the ozone treatment is inefficient ( lumbar stenosis, wryneck ... )

\section{2.- TECHNICAL ERRORS:}

A. Position of the needle ( paravertebral )

B. Wrong concentration of ozone 